\title{
Evidence-based or evidence-biased medicine?
}

\author{
Welcome to a new associate editor
}

\author{
Lodovico Balducci
}

Received: 4 September 2013 / Accepted: 24 October 2013/Published online: 1 November 2013

(C) Springer-Verlag Italia 2013

Perhaps the first example of "evidence-biased medicine" [1] was described by Alessandro Manzoni in his novel "I Promessi Sposi" (The Betrothed). In the 1600s, when the plague decimated the city of Milan, Don Ferrante was a learned man. Based on the scientific evidence of the time, supported by Aristotle's philosophy, he concluded that the plague could not possibly exist. The plague was neither a substance nor an accident, so it could not be classified, and consequently it could not possibly exist. Don Ferrante caught the plague and died while denying the very cause of his death.

Despite the development of the experimental method [2], evidence-biased medicine is still with us, every time that the experimental results are misinterpreted or misused. Some of the most egregious ways of misinterpreting evidence today include:

- Requests to prove the obvious. A few years ago the Journal of the International Association of Physicians in AIDS Care proposed that the cultists of evidencebased medicine accept to participate in a randomized controlled study in which a group of individuals would throw themselves from an airplane with a parachute and the other group without a parachute, as there is no type 1 evidence that parachutes save lives [3].

- Requests to prove the irrelevant, such as a study comparing Coke and Pepsi.

- Ignoring the potential diversity of disease. For example, adjuvant chemotherapy of breast cancer reduces breast cancer-related mortality based on a series of studies conducted during the past 40 years [4]. The results need

L. Balducci $(\bowtie)$

Tampa, USA

e-mail: lodovico.balducci@moffitt.org to be mitigated by recent advances in tumor biology identifying patients who do not benefit at all from chemotherapy [5]. Without this warning the existing evidence may lead to unnecessary toxicity and cost.

- Ignoring the variability of a highly diverse population, including the elderly [1]. It is virtually impossible to account for all the variables such as function, polymorbidity, and social support in the constraints of randomized controlled studies. Only registry studies with prospective collection of data may shed some light on the influence of these variables, such as the influence of diabetes on cancer growth [6] or functional independence on the tolerance of cytotoxic chemotherapy [7].

- Ignoring the limited power of so-called "non-inferiority" studies.

- Ignoring the so-called "soft variables" such as social support, spiritual and religious beliefs, family dynamic, communication skills that may influence goals of treatment, treatment adherence, and treatment outcome and are able to provide important diagnostic clues. Indeed, these variables represent the very substance of personalized medicine, the mission and the scope of this journal. These soft variables may be explored with qualitative research, by allowing a person to provide a narrative of her/his history. An important application of this type of research is exemplified by the religious order study [8] in which a number of nuns had pledged to donate their body for autopsy. Prior to joining the religious order each of these women wrote an essay explaining her decision to embrace religious life. Based on the style, the richness of thoughts and of words in these essays, a qualitative investigator was able to predict which of the nuns would be found to have signs of Alzheimer disease at autopsy. Another example is 
the instrument called FICA (faith: importance, community, assessment), which allows evaluation of the influence of religious beliefs on the patient's medical choices [9]. Other areas where qualitative research has provided unique information include assessment of personal values [10] and end-of-life care [11]. In this very issue I present an example of how narrative in medicine may help identify and manage the so-called "hateful patient" [12].

Given the relevance of qualitative research for our mission, and given the scarcity of qualitative research in the medical literature, I have decided to emphasize qualitative research in future issues. In my estimation, the Journal of Medicine and the Person has the potential to become the leading publication on qualitative research in medicine. Of course qualitative research will represent a mean to enrich the content of the journal, and to make it more congruent with its mission. In no way should it be constructed as an alternative to the traditional medical research or as a refusal of the scientific method.

To implement this plan I have asked Mariaelena Bartesaghi, PhD to join the Editorial Board. Dr. Bartesaghi is associate professor in the Department of Communication at the University of South Florida in Tampa, Florida and is a scholar of language in action, or language studied as social action, with material and embodied consequences. Despite her many academic commitments she has graciously agreed to join our effort. She will be responsible for analyzing studies of qualitative research submitted to the journal and to organize thematic issues based on narrative. On behalf of the Editorial Board and the readership I welcome Dr. Bartesaghi to our endeavor and thank her for her commitment.

\section{References}

1. Evans JC (1996) Evidence-based and evidence-biased medicine. Age Ageing 26:461-463

2. Spallanzani L (1780) Dissertazioni di fisica animale e vegetale. Societa' Tipografica, Modena

3. Smith GC, Pell JP (2004) Parachute use to prevent death and major trauma related to gravitational challenge: systematic review of randomized controlled trials. J Inten Assoc Physicians AIDS care 3:108-109

4. Early Breast Cancer Trialists collaborative group (2012) Comparison between different polychemotherapy regimens for early breast cancer: meta-analyses of long term outcome among 100,000.00 women in 123 clinical trials. Lancet 379:432-444

5. Carlson JJ, Roth JA (2013) The impact of oncotype DX breast cancer assay in clinical practice: a systematic review and metaanalysis. Breast cancer Res Treat, in press

6. Snyder CF, Stein KB, Barone BB et al (2010) Does pre-existing diabetes affect prostate cancer prognosis? A systematic review. Prostate Cancer Prostatic Dis 13:58-64

7. Extermann M, Boler I, Reich RR et al (2012) Predicting the risk of chemotherapy toxicity in older patients: the chemotherapy risk assessment scale for high age patients (CRASH). Cancer 118:3377-3386

8. Wilson RS, Schneider JA, Arnold SE et al (2007) Consciousness and the incidence of Alzheimer disease and od mild cognitive impairment. Arch Gen Psychiatry 64:1204-1212

9. Boneman T, Ferrell B, Puchalski C (2010) Evaluation of the FICA tool for spiritual assessment. J Pain Symptom Manage 40:163-173

10. Balducci L (2013) Values, the new medical mantra: misunderstood, abused, and underused. J Med Pers. doi:10-1007/s120682013-0148-Z

11. Tullis JA (2012) Personhood and communication at the end of life. J Med Pers. doi:10.1007/s12682-012-0131-0

12. Balducci L (2013) The hateful patient. J Med Pers. doi:10.1007/ s12682-013-0157-y 